\title{
Gearbox Life Cycle Assessment
}

\author{
Daizhong Su and Zhongming Ren \\ Advanced Design and Manufacturing Engineering Centre, \\ School of Architecture, Design, and Built Environment, \\ Nottingham Trent University, UK \\ Daizhong.su@ntu.ac.uk, Zhongming.ren2@ntu.ac.uk
}

\begin{abstract}
Sustainable production has been attracting more and more attention nowadays. Gearbox is a widely applied mechanical engineering product. However, little work of life cycle assessment (LCA) aimed at the gearbox could be found in the literature. This paper presents a LCA of gearbox to fill in the gap. The life cycle of the gearbox is modelled parametrically with a three-tier approach. Eco-impact caused by human labour is considered in the LCA. The LCA is conducted using a popular LCA software, SimaPro, and a widely accepted LCIA method, ReCiPe. Based on analysis of the results, optimisation plans are proposed at the end.
\end{abstract}

Keywords: Life cycle assessment, life cycle impact assessment, Gearbox, LCA, LCIA, SimaPro, ReCiPe, Environmental impact, Machinery, parametric modelling,

\section{Introduction}

In recent years, sustainable development have been risen as a popular topic, and sustainable production has been attracting more and more attention. Life cycle assessment (LCA) of mechanical engineering products has been considered as an important aspect of the sustainable production. Gearbox is a widely applied mechanical product in industry. However, according to the literature survey conducted by the authors, little work has been done for LCA of gearboxes. This paper presents a LCIA of representative single-stage gearbox to fill the gap.

In this research, a popular LCA software, SimaPro, and a well-known LCA method, ReCiPe, are used to conduct the LCA of the gearbox.

SimaPro has number of advanced features for LCA, such as friendly user interface, specific presentation of LCA results, and embedded ecoinvent database, which is a comprehensive Life Cycle Inventory (LCI) database. Furthermore, its parameter function provides the foundation of parametric modelling of the gearbox.

ReCiPe is a Life Cycle Impact Assessment (LCIA) method which comprises harmonised category indicators at the midpoint and the endpoint level. This method is an improvement on CML 2001 method [1] and Eco-indicator 99 method [2]. The method calculates eighteen midpoint indicators and sum up these midpoint indicators into three endpoint indicators. Because the eighteen midpoint indicators are not easy to interpret, the three endpoint indicators are more understandable. User can choose at which level it wants to have the result. [3]

\section{Parametric Modelling of the Gearbox Life Cycle}

A single-stage industrial gearbox, as shown in Fig. 1, is taken as the object of the LCA. The modelling mainly consists of two stages, modelling of the assembly and its production, and the rest of phases within the product life cycle, including transport, disposal, disassembly, and waste scenario.

The parameter function provided within the SimaPro has two modules, 'input parameters' and 'calculated parameters'. Parameters' name and their values can be defined by user in the 'input parameters'. In the calculated parameters, new complicated parameters can be defined as expressions of input parameters listed previously. Meanwhile, these parameters will be calculated simultaneously and automatically by SimaPro. The function offers the foundation of the parametric modelling of the life cycle.

The parametric modelling of the assembly and its production are divided into two aspects, material extraction and mechanical process. The ecoinvent database contains life cycle inventory of mainstream material extractions and mechanical processes. With the help of ReCiPe LCIA method, these inventories can be converted into environmental impact per unit of mass. Therefore, mass of material extraction and mechanical process of each part should be defined firstly. All geometry dimensions of each part are defined in the input parameters module and volume of blanks and processed parts are expressed as formations of input parameters in calculated parameters module. With density of each kind of material, the mass can be obtained accordingly.

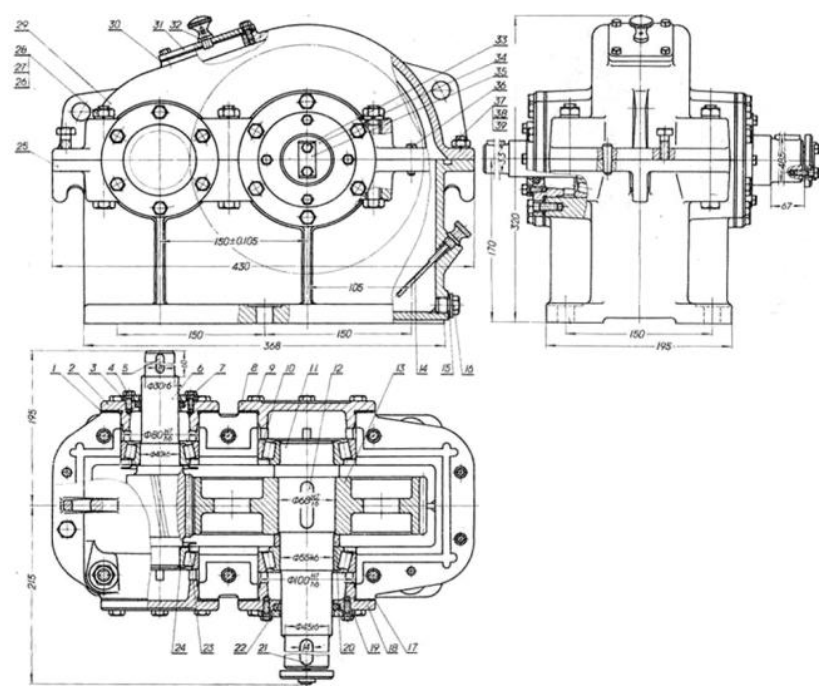

Fig. 1. Gearbox assembly drawing [4] 
Following the Three-tiers approach for calculation of LCIA scores proposed in [5], the gearbox assembly is broken into three tiers as shown in Fig. 2: (1) parts, including one spur gear, one high speed shaft, one low speed shaft, two bearings for low speed shaft, two bearings for high speed shaft, five kinds of bolts, two kinds of nuts, one case base, one case cover, and four bearing end caps, etc. (2) sub-assemblies, including high speed shaft assembly, low speed shaft assembly, case, bolts, and nuts; and (3) assembly, i.e., the gearbox. All the parts, subassemblies, and assembly are set up as parametric models in mentioned method. The impact of them will be summed up tier by tier to form the impact of the assembly.

After that, all amounts that the materials used for blanks of parts and cut off by each manufacture process are taken into account. All these mass data are inputted in corresponding extraction or manufacture process in input/output module of the SimaPro. In addition, human labour impact [5] involved in the production of each part are considered as well.

The modelling of the rest phases within the life cycle, including transport, disposal, disassembly, and waste scenario of gearbox are completed in corresponding modules provided by SimaPro. For the disposal of the gearbox after the end of its life, all the parts are assumed to be treated as waste scenario, which is a waste distribution list indicated different waste treatments for different waste types in England, provided by PRé in SimaPro.

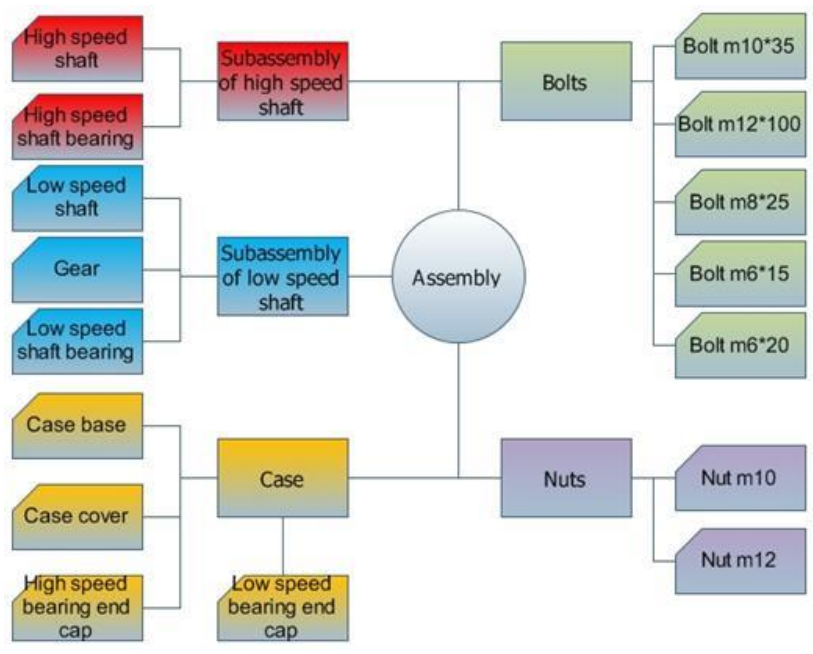

Fig.2. Gearbox assembly breakdown structure

\subsection{Modelling of the gearbox assembly}

As shown in Fig. 2, the gearbox assembly is consist of five subassemblies. Each subassembly has number of parts. There are sixteen kinds of parts. Some subassemblies have more than one piece of a kind of part. Such as bearings and bearing end caps, they are always assembled in couples. Also, numbers of bolts and nuts are assembled to tighten the case base and case cover. Completed list of parts is illustrated in Table 1. In total, there are 68 parts. In each stage of modelling, number of parts will be multiplied and taken into account of whole results of LCIA.

\begin{tabular}{|c|c|c|}
\hline Subassembly & Part & Piece \\
\hline \multirow{2}{*}{$\begin{array}{l}\text { subassembly of high } \\
\text { speed shaft }\end{array}$} & high speed shaft & 1 \\
\hline & high speed shaft bearing & 2 \\
\hline \multirow{3}{*}{$\begin{array}{l}\text { subassembly of low } \\
\text { speed shaft }\end{array}$} & low speed shaft & 1 \\
\hline & low speed shaft bearing & 2 \\
\hline & gear & 1 \\
\hline \multirow{4}{*}{ case } & case base & 1 \\
\hline & case cover & 1 \\
\hline & high speed bearing end cap & 2 \\
\hline & low speed bearing end cap & 2 \\
\hline \multirow{5}{*}{ Bolts } & bolt $\mathrm{m} 10 * 35$ & 3 \\
\hline & bolt $\mathrm{m} 12 * 100$ & 6 \\
\hline & bolt $\mathrm{m} 8 * 25$ & 24 \\
\hline & bolt $\mathrm{m}^{*} * 20$ & 2 \\
\hline & bolt $\mathrm{m} 6 * 15$ & 12 \\
\hline \multirow[t]{2}{*}{ Nuts } & nut m10 & 2 \\
\hline & nut $\mathrm{m} 12$ & 6 \\
\hline Total & & 68 \\
\hline
\end{tabular}

Table 1 Parts list of each subassembly

\subsubsection{Part modelling}

Modelling in SimaPro uses parametric manner as mentioned. Each parameter must have a unique name in the whole project to avoid confusion. The ecological impact comes from two sections, material extraction and process. The modelling of parts is based on this principle. The extraction of used material and manufacture process amount will be modelled for each part.

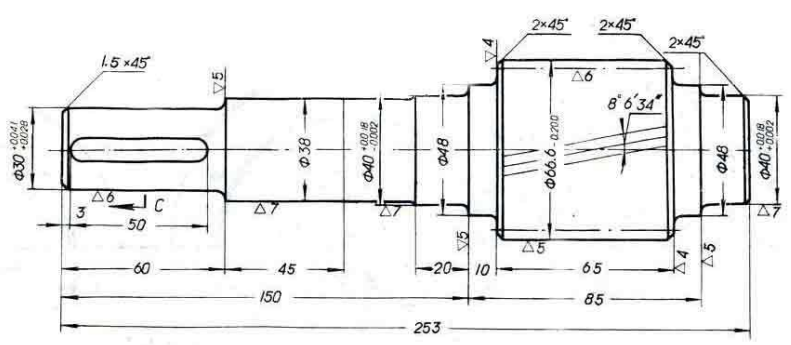

Fig. 3 drawing of the shaft [4]

High speed shaft is a gear-shaft made by low-alloyed steel as shown in Fig. 3. Mass of material used for blank is a calculated parameter named blank_mass, which is calculated from input parameters below as Table 2. The blank_mass is obtained by blank_volume multiples density of the material, AISI1040, which is estimated as $7.85 \mathrm{e}-6 \mathrm{~kg} / \mathrm{mm}^{3}$. The density is valued by the average value of the range of density from $7.8 \mathrm{e}-6$ to $7.9 \mathrm{e}-6$ $\mathrm{kg} / \mathrm{mm}^{3}$. Blank_volume is the volume of a cylinder metal blank. The formula to calculate the volume is shown below and in Table 2 .

$$
\text { blank_volume }=\frac{\pi}{4} * \text { blank_diameter }{ }^{2} * \text { blank_length }
$$

Input parameters include the length and diameter of the blank, blank_length and blank_diameter, and five different length and diameter of each stage of the gearshaft, $g s_{-} L 1, g s_{-} L 2, g s_{-} L 3, g s_{-} L 4, g s_{-} L 5, g s_{-} d 1, g s_{-} d 2$, $g s \_d 3, g s \_d 4, g s \_d 5$. Calculated parameters include the volume and mass of the blank, and the volume of gearshaft, gear-shaft_volume, which is calculated from input parameters as shown in formula (2).

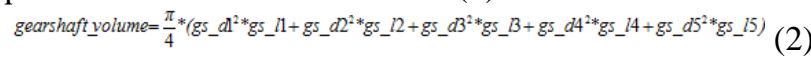

And then, the scrap cut off during the process of gearshaft manufacture is obtained. $g s \_s c r a p \_v$ is the volume of the scrap which is equal to the difference between that of the blank and that of the gear-shaft. The mass of the 
scrap, $g s \_s c r a p \_m$, is acquired by multiplying the density of the material.

\begin{tabular}{|c|c|c|}
\hline Name & $\overline{\text { Value }}$ & Unit \\
\hline \multicolumn{3}{|l|}{ high speed shaft } \\
\hline \multicolumn{3}{|l|}{$\begin{array}{c}\text { Materials/Asse } \\
\text { mblies }\end{array}$} \\
\hline $\begin{array}{l}\text { Steel, low- } \\
\text { alloyed, at } \\
\text { plant/RER U }\end{array}$ & blank_mass & $\mathrm{kg}$ \\
\hline \multicolumn{3}{|l|}{ Processes } \\
\hline $\begin{array}{l}\text { Turning, steel, } \\
\text { conventional, } \\
\text { average/RER U }\end{array}$ & gs_scrap_m- 0.1 & $\mathrm{~kg}$ \\
\hline $\begin{array}{l}\text { Milling, steel, } \\
\text { average/RER U }\end{array}$ & 0.1 & $\mathrm{~kg}$ \\
\hline Human labour & 1 & $\mathrm{hr}$ \\
\hline \multicolumn{3}{|l|}{$\begin{array}{c}\text { Input } \\
\text { parameters }\end{array}$} \\
\hline blank_length & 253 & $\mathrm{~mm}$ \\
\hline blank_diameter & 70 & $\mathrm{~mm}$ \\
\hline gs_L1 & 60 & $\mathrm{~mm}$ \\
\hline gs_L2 & 70 & $\mathrm{~mm}$ \\
\hline gs_L3 & 38 & $\mathrm{~mm}$ \\
\hline gs_L4 & 20 & $\mathrm{~mm}$ \\
\hline gs_L5 & 65 & $\mathrm{~mm}$ \\
\hline gs_d1 & 30 & $\mathrm{~mm}$ \\
\hline gs_d2 & 38 & $\mathrm{~mm}$ \\
\hline gs_d3 & 40 & $\mathrm{~mm}$ \\
\hline gs_d4 & 48 & $\mathrm{~mm}$ \\
\hline gs_d5 & 65 & $\mathrm{~mm}$ \\
\hline \multicolumn{3}{|l|}{$\begin{array}{l}\text { Calculated } \\
\text { parameters }\end{array}$} \\
\hline blank_volume & pi/4*blank_diameter^ ${ }_{\text {gth }} 2 *$ blank_len & $\mathrm{mm}^{\wedge} 3$ \\
\hline $\begin{array}{l}\text { gear- } \\
\text { shaft_volume }\end{array}$ & 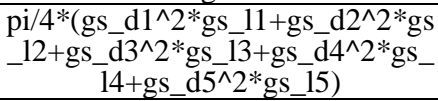 & $\mathrm{mm}^{\wedge} 3$ \\
\hline gs_scrap_v & blank_volume-gear-shaft_volume & $\mathrm{mm}^{\wedge} 3$ \\
\hline blank_mass & blank_volume*7.85e-6 & $\mathrm{kg}$ \\
\hline gs_scrap_m & gs_scrap_v*7.85e-6 & $\mathrm{kg}$ \\
\hline
\end{tabular}

Table 2 High speed shaft modelling parameters

Low speed shaft is a shaft as shown in the bottom of Table 3. Material of blank is same as the high speed shaft. Mass of material used for blank is a calculated parameter named blank_m, which is calculated from input parameters below as Table 3. The blank $\_m$ is obtained by blank_v multiples density of the material, which is same as the high speed shaft. The blank_v is the volume of a cylinder metal blank. The formula to calculate the volume is shown below and in Table 3.

$$
\text { blank_v }=\frac{\pi}{4} * \text { blank_d }{ }^{2} * \text { blank_l }
$$

Input parameters include the length and diameter of the blank, blank_l and blank_d, and five different length and diameter of each stage of the shaft, $s_{-} l 1, s_{-} l 2, s_{-} l 3, s_{-} l 4$, $s \_l 5, s \_d 1, s \_d 2, s \_d 3, s \_d 4, s \_d 5$. Calculated parameters include the volume and mass of the blank, and the volume of shaft, shaft_v, which is calculated from input parameters through formula 4.

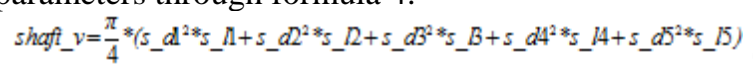

And then, the scrap cut off during the process of shaft manufacture is obtained. $s_{-} s c r a p \_v$ is the volume of the scrap which is equal to the difference between that of the blank and that of the shaft. The mass of the scrap, $s \_s c r a p \_m$, is acquired by multiplying the density of the material. During the process of shaft manufacture, the scrap is cut off by turning and milling. $0.1 \mathrm{~kg}$ is estimated as the mass of milling, which is finishing processing. The remind mass of scrap is the mass of turning. As the table shows, turning mass is equal to $s \_s c r a p \_m-0.1 \mathrm{~kg}$. Human labour used for manufacture of low speed shaft is about one hour.

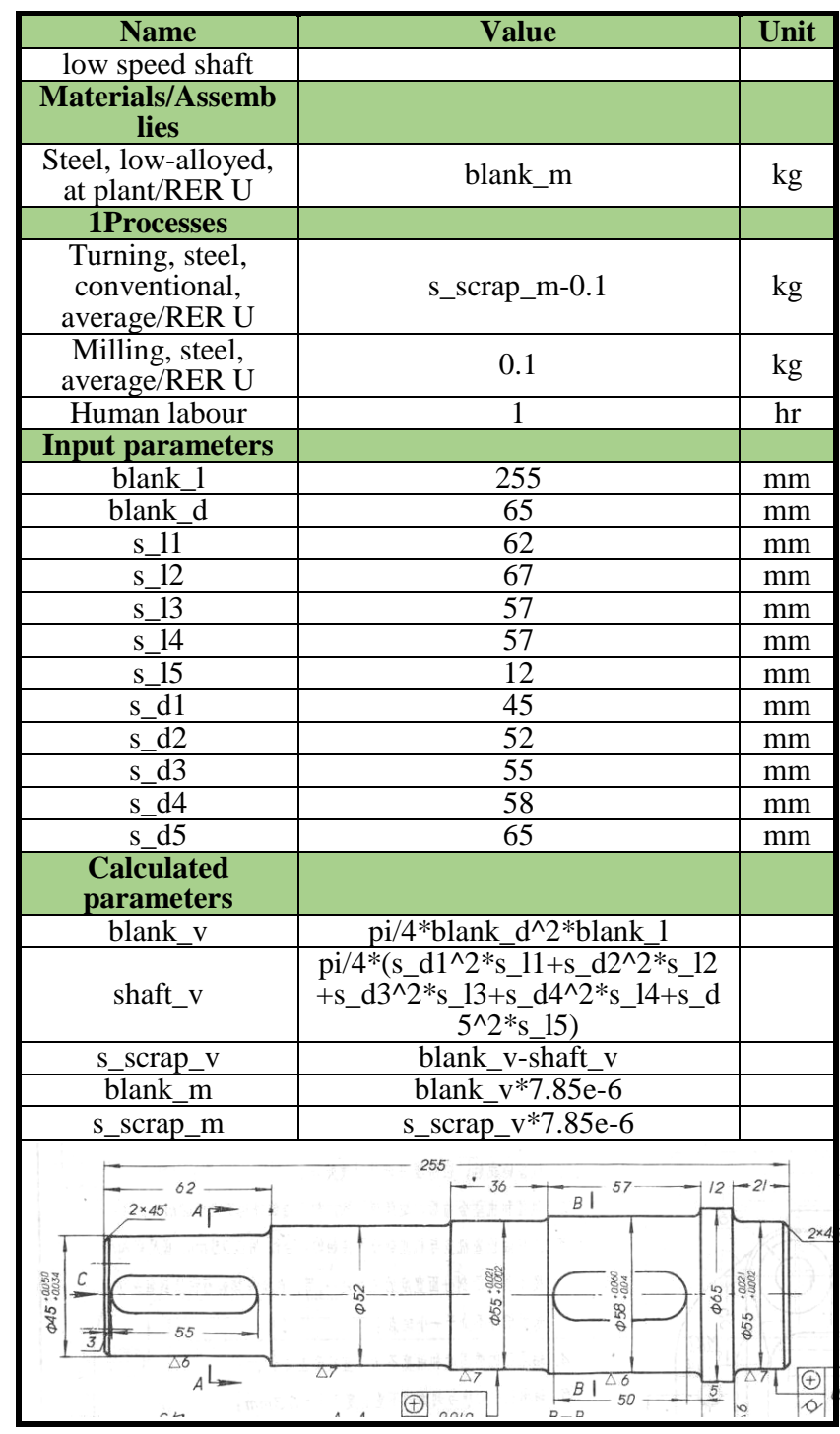

Table 3 Low speed shaft modelling parameters

Gear is perforated as shown in the bottom of Fig. 3 . Material of blank is the same as the high speed shaft. Mass of material used for blank is a calculated parameter named $b \_m$. The $b \_m$ is obtained by $b \_v$ multiples density of the material, which is same as the high speed shaft. The $b_{-} v$ is the volume of a cylinder metal blank, which is calculated from input parameters through formula 5 shows below and in Table 4 .

$$
b_{-} v=\frac{\pi}{4} * b_{-} d^{2} * b_{-} l
$$

Input parameters include the length and diameter of the blank, $b \_l, b \_d$, amount, length and diameter of holes, $h \_a, h \_l, h \_d$, two diameters and depth of the ring groove, $r_{-} d 1, r_{-} d 2, r_{-} l$, length and diameter of centre hole, $c h \_l$, $c h \_d$. Calculated parameters include the volume and mass of the blank and the gear, and the volume of holes, ring groove, and centre hole, $h_{-} v, r_{-} v, c h \_v$. which are calculated from input parameters through formula 6,7 and 8 .

$$
h \_v=\frac{\pi}{4} \times h d^{2} \times h l_{-} \times h \_a
$$




$$
\begin{gathered}
r_{-} v=\frac{\pi}{4} \times\left(r_{-} d 2-r_{-} d 1\right)^{2} \times r_{-} l \\
r_{-} v=\frac{\pi}{4} \times\left(r_{-} d 2-r_{-} d 1\right)^{2} \times r_{-} l \\
g_{-} v=b_{-} v-\left(h \_v+r_{-} v+c h \_v\right)
\end{gathered}
$$

And then, the volume of gear, $g_{-} v$ is calculated by the volume of the blank minus the sum of the volume of the holes, ring groove, and centre hole. The formula 9 is shown above. Then, the scrap cut off during the process of the gear manufacture is obtained. $s c r a p \_m$ is the mass of

\begin{tabular}{|c|c|c|}
\hline Name & Value & Unit \\
\hline \multicolumn{3}{|l|}{ gear } \\
\hline \multicolumn{3}{|l|}{ Materials/Assemblies } \\
\hline $\begin{array}{c}\text { Steel, low-alloyed, at } \\
\text { plant/RER U }\end{array}$ & b_m & $\mathrm{kg}$ \\
\hline \multicolumn{3}{|l|}{ Processes } \\
\hline $\begin{array}{l}\text { Turning, steel, conventional, } \\
\text { average/RER U }\end{array}$ & scrap_m-1 & $\mathrm{kg}$ \\
\hline $\begin{array}{c}\text { Milling, steel, average/RER } \\
\text { U }\end{array}$ & 1 & $\mathrm{~kg}$ \\
\hline Human labour & 1 & $\mathrm{hr}$ \\
\hline \multicolumn{3}{|l|}{ Input parameters } \\
\hline b_l & 60 & $\mathrm{~mm}$ \\
\hline b_d & 237 & $\mathrm{~mm}$ \\
\hline h_d & 35 & $\mathrm{~mm}$ \\
\hline h_a & 6 & $\mathrm{~mm}$ \\
\hline h_l & 15 & $\mathrm{~mm}$ \\
\hline r_d1 & 210 & $\mathrm{~mm}$ \\
\hline r_d2 & 90 & $\mathrm{~mm}$ \\
\hline$\overline{\mathrm{r}} \_1$ & 45 & $\mathrm{~mm}$ \\
\hline ch_d & 58 & $\mathrm{~mm}$ \\
\hline ch_1 & 60 & $\mathrm{~mm}$ \\
\hline \multicolumn{3}{|l|}{ Calculated parameters } \\
\hline b_v & pi/4*b_d^2*b_1 & \\
\hline h_v & pi/4*h_d^2*h_l*h_a & \\
\hline $\mathrm{r} \_\mathrm{V}$ & $\mathrm{pi} / 4 *\left(\mathrm{r} \_\mathrm{d} 2-\mathrm{r} \_\mathrm{d} 1\right)^{\wedge} 2 * \mathrm{r} \_1$ & \\
\hline ch_v & $\mathrm{pi} / 4 * \mathrm{ch} \_\mathrm{d}^{\wedge} 2 * \mathrm{ch} \_1$ & \\
\hline g_v & b_v-(h_v+r_v+ch_v) & \\
\hline b_m & b_v*7.85e-6 & \\
\hline g_m & g_v*7.85e-6 & \\
\hline scrap_m & b_m-g_m & \\
\hline
\end{tabular}
the scrap which is equal to the difference between that of the blank and that of the gear.

Table 4. Gear modelling parameters

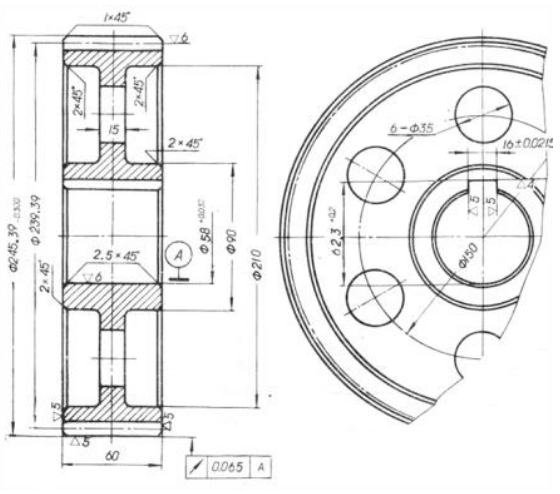

Fig. 3. Gear [4]

Case base is the base of the gearbox as shown in Fig. 4. Material used is cast iron. Mass of material used is a calculated parameter $c b \_m$ - bec_ $m$, which is the difference from mass of case base and mass of the holes cut off for assembling bearing end caps. They are all calculated from input parameters below as Table 5. The $c b \_m$ is obtained by $c b \_v$ multiples density of the material, which is estimated as $7.125 \mathrm{e}-6 \mathrm{~kg} / \mathrm{mm}^{3}$. The density is valued by the average value of the range of density from $7.05 \mathrm{e}-6$ to $7.2 \mathrm{e}-6 \mathrm{~kg} / \mathrm{mm}^{3}$. The $c b \_v$ is the volume used to make cast iron. The formula to calculate the volume is shown below and in Table 5. The volume is equal to the difference from the cube outside to the cube inside of the case.

$$
c b_{-} v=c b_{-} l \times c b \_w \times c b_{-} h-\left(c b \_t c b \_t\right) \times\left(c b_{-} w-c b \_\times\left(c b{ }_{-} h-c b \_\right. \text {(10) }\right.
$$

Input parameters include the length, $c b_{-} l$, width, $c b_{-} w$, height, $c b \_h$, and thickness, $c b \_t$, of the case base, and five different lengths of bolts, $l 1, l 2, l 3, l 4, l 5$, which are assembled in the case to tighten the case base and case cover. For convenient calculation, all the bolts are calculated with the case base but not case cover. Two diameters of two holes for assembling bearing end caps, $s b e c \_d, l b e c \_d$, are also included in the input parameters. Calculated parameters include the volume and mass of the case base, all the holes for assembling the bolts, hole_v, $h o l e \_m$, and bearing end caps, $b e c \_v, b e c \_m$. They are all calculated from input parameters. The hole_v and $b e c_{-} v$ is calculated from formula shown below.

$$
\begin{gathered}
\text { hole_ }=\frac{\pi}{4} \times 6^{2} \times(l 2 \times 2+l 1 \times 12)+\frac{\pi}{4} \times 8^{2} \times 24 \times 13+\frac{\pi}{4} \times 10^{2} \times l 4 \times 3+\frac{\pi}{4} \times 12^{2} \times l 5 \times 6 \\
\text { bec_ } v=\frac{\pi}{4} c c_{-} t \times\left(\text { sbec_ } d^{2}+l b e c d^{2}\right)
\end{gathered}
$$

During the process of case base manufacture, the mass of holes, hole_m, is processed by drilling. Before drilling

\begin{tabular}{|c|c|c|}
\hline Name & Value & Unit \\
\hline case base & & \\
\hline \multicolumn{3}{|l|}{$\begin{array}{c}\text { Materials/Assembl } \\
\text { ies }\end{array}$} \\
\hline $\begin{array}{l}\text { Cast iron, at } \\
\text { plant/RER U }\end{array}$ & cb_m-bec_m & $\mathrm{kg}$ \\
\hline \multicolumn{3}{|l|}{ Processes } \\
\hline $\begin{array}{l}\text { Drilling, } \\
\text { conventional, cast } \\
\text { iron/RER U }\end{array}$ & hole_m & $\mathrm{kg}$ \\
\hline $\begin{array}{l}\text { Heat treatment, hot } \\
\text { impact extrusion, } \\
\text { steel/RER U }\end{array}$ & cb_m-bec_m & $\mathrm{kg}$ \\
\hline $\begin{array}{l}\text { Turning, cast iron, } \\
\text { conventional, } \\
\text { average/RER U }\end{array}$ & 1 & $\mathrm{~kg}$ \\
\hline Human labour & 2 & $\mathrm{hr}$ \\
\hline \multicolumn{3}{|l|}{ Input parameters } \\
\hline cb_l & 428 & $\mathrm{~mm}$ \\
\hline cb_w & 190 & $\mathrm{~mm}$ \\
\hline cb_h & 170 & $\mathrm{~mm}$ \\
\hline $\mathrm{cb} \_\mathrm{t}$ & 8 & $\mathrm{~mm}$ \\
\hline 11 & 15 & $\mathrm{~mm}$ \\
\hline 12 & 20 & $\mathrm{~mm}$ \\
\hline 13 & 25 & $\mathrm{~mm}$ \\
\hline 14 & 35 & $\mathrm{~mm}$ \\
\hline 15 & 100 & $\mathrm{~mm}$ \\
\hline sbec_d & 80 & $\mathrm{~mm}$ \\
\hline lbec_d & 100 & $\mathrm{~mm}$ \\
\hline \multicolumn{3}{|l|}{$\begin{array}{l}\text { Calculated } \\
\text { parameters }\end{array}$} \\
\hline cb_v & $\begin{array}{c}c b \_l * c b \_w * c b \_h-\left(c b \_l-\right. \\
\left.c b \_t\right) *\left(c b \_w-c b \_t\right) *\left(c b \_h-c b \_t\right)\end{array}$ & \\
\hline $\mathrm{cb} \_\mathrm{m}$ & cb_v*7.125e-6 & \\
\hline hole_v & $\begin{array}{c}\mathrm{pi} / 4 * 6^{\wedge} 2^{*}\left(12^{*} 2+11 * 12\right)+\mathrm{pi} / 4 * 8^{\wedge} 2 \\
* 24 * 13+\mathrm{pi} / 4 * 10^{\wedge} 2 * 14 * 3+\mathrm{pi} / 4 * 12^{\wedge} \\
2 * 15^{*} 6\end{array}$ & \\
\hline hole_m & hole_v*7.125e-6 & \\
\hline bec_v & pi $/ 4 *$ cb_t ${ }^{*}\left(\right.$ sbec_d d $\left.2+1 b e c \_d^{\wedge} 2\right)$ & \\
\hline bec_m & bec_v*7.125e-6 & \\
\hline
\end{tabular}
holes, the case base should be processed by heat treatment. Turning is the finish process to plain the surface of the case base. The weight processed by turning is $1 \mathrm{~kg}$. Human labour used for manufacture of case base is two hours. 
Table 7 High speed bearing end cap modelling parameters

During the process of end cap manufacture, turning is the finish process to plain the surface of the end cap. The weight processed by turning is $0.1 \mathrm{~kg}$. Human labour used for manufacture of end cap is half an hour. The modelling of low speed bearing end cap is similar as that of high speed bearing end cap.

High speed shaft bearing is the bearing of high speed shaft as shown in Table 8 . It is a $7208 \mathrm{c}$ angular contact ball bearing of GB/T 292-1994 standard. Material used is chromium steel. Mass of material used is a calculated parameter, $m$, which is calculated from volume of material used and the density of the chromium steel, which is estimated as $8 \mathrm{e}-6 \mathrm{~kg} / \mathrm{mm}^{3}$. The density is valued by the average value of the range of density from $7.93 \mathrm{e}-6$ to $8.09 \mathrm{e}-6 \mathrm{~kg} / \mathrm{mm}^{3}$. The $v$ is the volume used to make chromium steel blank. The formula to calculate the volume shows below and in Table 8 . The volume of blank is equal to the volume of whole cylinder.

$$
v=\frac{\pi}{4} \times b \times\left(c d^{2}-d^{2}\right)
$$

Input parameters include four diameters, $d, d 2, c d, c d 2$, and the thickness of the bearing, $b$. Calculated parameters include the volume and mass of the blank, $v$ and $m$. Based on the GB/T 292-1994 standard of 7208c angular contact ball bearing. The mass of the final bearing is about $0.37 \mathrm{~kg}$.

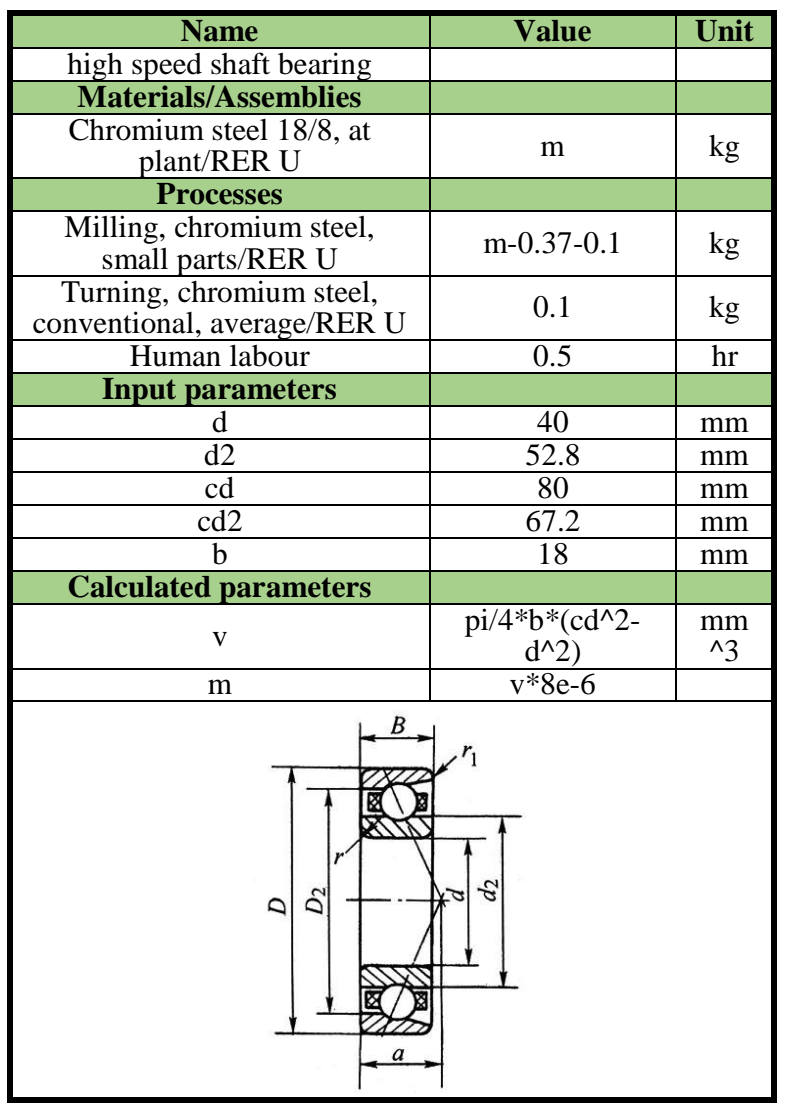

Table 8 High speed shaft bearing modelling parameters

During the process of bearing manufacture, milling is the finish process. The weight processed by milling is $\mathrm{m}-$ $0.37-0.1$. Which is equal to the mass of blank subtracts the mass of the bearing, 0.37 , and mass processed by turning, $0.1 \mathrm{~kg}$. Human labour used for manufacture of bearing is half an hour. The modelling of low speed shaft bearing is similar as that of high speed shaft bearing.

\subsubsection{Subassembly and assembly modelling}

As shown in Table 1, there are five subassemblies in the gearbox including subassembly of high speed shaft, subassembly of low speed shaft, case, bolts, and nuts. As Table 11 shows, each subassembly defines kind and amount of part and time spend of human labour for assembling parts together.

Modelling of subassembly in the SimaPro is to integrate all parts and time spent for assembling these parts together. For example, modelling of subassembly of bolts consists of two steps including add corresponding amounts of five different types of bolts into the subassembly and add time spend for assembling these bolts to the case. The subassembly of bolts consists of three $\mathrm{m} 10 * 35$ bolts, six $\mathrm{m} 12 * 100$ bolts, twenty-four $\mathrm{m} 8 * 25$ bolts, $2 \mathrm{~m} 6 * 20$ bolts, $12 \mathrm{~m} 6 * 15$ bolts, and $15 *(3+6+24+2+12)=705$ s human labour.

Time spends of assembling one bolt and one nut are estimated as 15 and 10 seconds respectively. Other modelling of subassembly have similar processes. Totally, there are 68 parts in all of these subassemblies, and $17 \mathrm{~min} 5 \mathrm{~s}$ is spent to assemble these subassemblies.

\begin{tabular}{|c|c|c|c|}
\hline Subassembly & Part & Piece & $\begin{array}{l}\text { Human } \\
\text { labour }\end{array}$ \\
\hline \multirow[b]{2}{*}{$\begin{array}{l}\text { subassembly of } \\
\text { high speed shaft }\end{array}$} & high speed shaft & 1 & \multirow[b]{2}{*}{$1 \mathrm{~min}$} \\
\hline & $\begin{array}{l}\text { high speed shaft } \\
\text { bearing }\end{array}$ & 2 & \\
\hline \multirow{3}{*}{$\begin{array}{l}\text { subassembly of } \\
\text { low speed shaft }\end{array}$} & low speed shaft & 1 & \multirow{3}{*}{$2 \mathrm{~min}$} \\
\hline & $\begin{array}{l}\text { low speed shaft } \\
\text { bearing }\end{array}$ & 2 & \\
\hline & gear & 1 & \\
\hline \multirow{4}{*}{ case } & case base & 1 & \multirow{4}{*}{$1 \mathrm{~min}$} \\
\hline & case cover & 1 & \\
\hline & $\begin{array}{c}\text { high speed } \\
\text { bearing end cap }\end{array}$ & 2 & \\
\hline & $\begin{array}{l}\text { low speed bearing } \\
\text { end cap }\end{array}$ & 2 & \\
\hline \multirow{5}{*}{ bolts } & bolt $\mathrm{m} 10 * 35$ & 3 & \multirow{5}{*}{$705 \mathrm{~s}$} \\
\hline & bolt m12*100 & 6 & \\
\hline & bolt $\mathrm{m} 8 * 25$ & 24 & \\
\hline & bolt $\mathrm{m} 6 * 20$ & 2 & \\
\hline & bolt $\mathrm{m} 6 * 15$ & 12 & \\
\hline \multirow{2}{*}{ nuts } & nut $\mathrm{m} 10$ & 2 & \multirow{2}{*}{$80 \mathrm{~s}$} \\
\hline & nut m12 & 6 & \\
\hline Total & & 68 & $17 \min 5 s$ \\
\hline
\end{tabular}

Table 11 Subassembly modelling

The assembly is the gearbox. As Table 12 shows, modelling of assembly integrates all of the subassemblies together and add processes used during assembly. Assembly includes one for each subassembly modelling above. Processes used include 2 min human labour for assemble and $0.01 \mathrm{kWh}$ electricity for lifting parts up.

\begin{tabular}{|c|c|c|}
\hline Name & Value & Unit \\
\hline Original Gearbox & & \\
\hline Materials/Assemblies & 1 & $\mathrm{p}$ \\
\hline case & 1 & $\mathrm{p}$ \\
\hline $\begin{array}{c}\text { subassembly of low speed } \\
\text { shaft }\end{array}$ & 1 & $\mathrm{p}$ \\
\hline $\begin{array}{c}\text { subassembly of high speed } \\
\text { shaft }\end{array}$ & 1 & $\mathrm{p}$ \\
\hline Bolts & 1 & $\mathrm{p}$ \\
\hline Nuts & 2 & $\mathrm{~min}$ \\
\hline Process & $\mathrm{kWh}$ \\
\hline $\begin{array}{c}\text { Electricity, medium voltage, } \\
\text { production GB, at grid/GB U }\end{array}$ & 0.01 & $\mathrm{kn}$ labour \\
\hline \multicolumn{2}{|c|}{}
\end{tabular}

Table 12 Assembly modelling 


\subsection{Modelling of the life cycle}

The life cycle of original gearbox includes one piece of gearbox, transport to retailer by van, disposal of the gearbox, and one additional life cycle of lubricating oils and greases. The transport is operated by a van with less than 3.5 ton weight load. Distance from factory to the retailer is 10 kilometres. The additional life cycle of lubricating oils and greases lasts one year. It will be replaced by new lubricating oils and greases once per year.

\begin{tabular}{|c|c|c|}
\hline Name & Value & Unit \\
\hline Original Gearbox life cycle & & \\
\hline Assembly & & \\
\hline Original Gearbox & 1 & $\mathrm{p}$ \\
\hline Processes & & \\
\hline Operation, van < 3,5t/RER U & 10 & $\mathrm{~km}$ \\
\hline Waste/Disposal scenario & & \\
\hline disposal of original gearbox & & \\
\hline
\end{tabular}

\section{Table 13 Life cycle modelling}

Disposal of original gearbox refers to the gearbox assembly. Two hours human labour during the disposal process is added into the disposal as well. The waste scenario is estimated as $100 \%$ disassembly of the gearbox. The disassembly of the gearbox is referred to the assembly to set up connection between it to the assembly. One hour human labour is consumed during the process of disassembly of the gearbox. The separation of subassemblies is not considered for the original gearbox. All the waste for the original gearbox is treated by waste scenario for England. The waste scenario for England indicates waste flow for different type of waste in the end life of the product in England.

\section{LCA Results Interpretation}

After the modelling of the gearbox life cycle, hierarchist version of the ReCiPe method with normalisation value of world and the average weighting set are selected to assess the model.
The network results of LCIA are shown in Fig. 6 . Yellow box in figure refers to the life cycle of original gearbox. Light blue boxes refer to subassemblies and parts. The grey boxes refer to processes used. For better present of the network, $4 \%$ cut-off is applied. That means any impact less than $4 \%$ of all have been cut off and hide. Each process has a numerical reading of eco-indicator in left bottom and a red colour bar indicator diagram in right side. A larger reading and larger red bar represent a larger ecological impact that the process generated. Also, a wider arrow represents larger ecological impact flows in and out. Percentage of each box clearly indicates how much impact is shared by individual process, part, or subassembly. As the figure shows, cast iron, chromium steel, low-alloyed steel and turning process on steel has the most of ecological impact among all the processes and material used in the gearbox life cycle. They score $6.52 \mathrm{Pt}$, 2.52Pt, 11.5Pt, and 4.49Pt and 25.5\%, 9.86\%, 45\%, $17.6 \%$ of all ecological impact respectively. Obviously, the lowalloyed steel has the most impact. Nearly half impact is contributed by the extraction of the low-alloyed steel. The cast iron contributes to case base, case cover, and low speed bearing end. Actually, it also contributes to high speed bearing end but it is not displayed since the $4 \%$ cutoff. The chromium steel contributes to low speed shaft bearing and high speed shaft bearing. The low-alloyed steel contributes to low speed shaft, gear, and high speed shaft. And it also processed by turning besides it. The turning contributes to the gear, the low speed shaft, the high speed shaft. And it also contributes to the lowalloyed steel as mentioned before.

Focusing on parts, which are light blue boxes shown above the grey process boxes, the gear shares the most ecological impact among them. Which is $7.41 \mathrm{Pt}$ sharing $29.2 \%$ of all. The high speed shaft bearing and low speed bearing end have almost the least ecological impact, which are 1. $05 \mathrm{Pt}$. sharing $4.12 \%$ and $1.06 \mathrm{Pt}$. sharing $4.19 \%$ respectively. The high speed shaft has the second high ecological impact of all these subassemblies, which

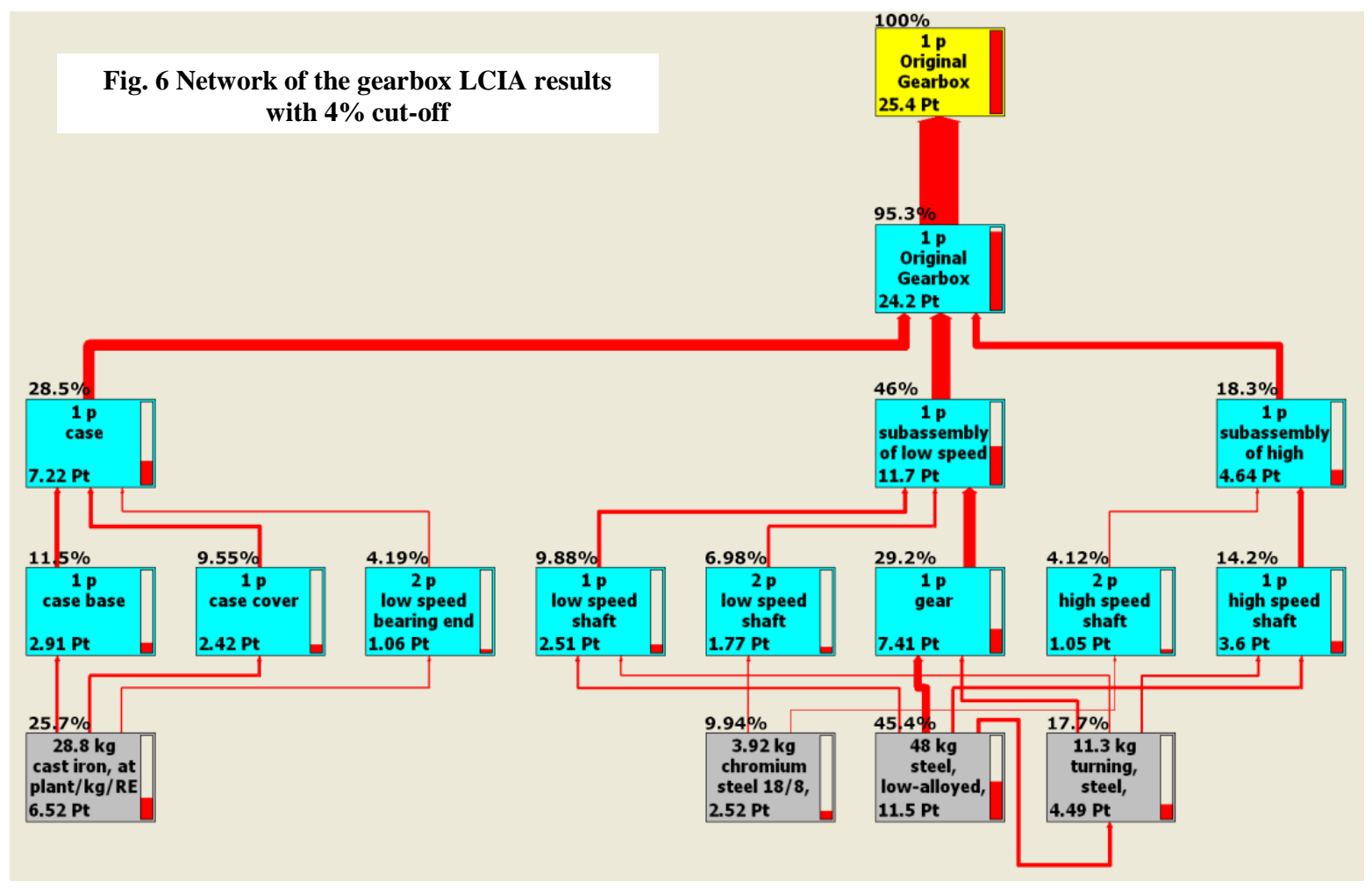


is $3.6 \mathrm{Pt}$. sharing $14.2 \%$.The case base has the third high ecological impact of all these subassemblies, which is 2.91 Pt. sharing $11.5 \%$. The ecological impact of case cover and low speed shaft are almost the same, which are $2.42 \mathrm{Pt}$. sharing 9.55\% and 2.51 Pt. sharing 9.88\%. The two pieces of low speed shaft bearing has $1.77 \mathrm{Pt}$. ecological impact, which shares $6.98 \%$.

Focusing on subassemblies, the subassembly of low speed has the highest impact as $11.7 \mathrm{Pt}$. sharing $46 \%$. The main reason is the gear has the highest ecological impact. The case and the subassembly of high speed got second and third high ecological impact score, which are 7.22 Pt. sharing $28.5 \%$ and 4.64 Pt. sharing $18.3 \%$.

The manufacture of gearbox assembly which is shown as the light blue box named original gearbox contains 95.3 $\%$ ecological impact of all processes in the gearbox life cycle. That means transport, disposal of gearbox, disassembly of gearbox, additional life cycle of lubricating oils and greases have remaining $4.7 \%$ of ecological impact.

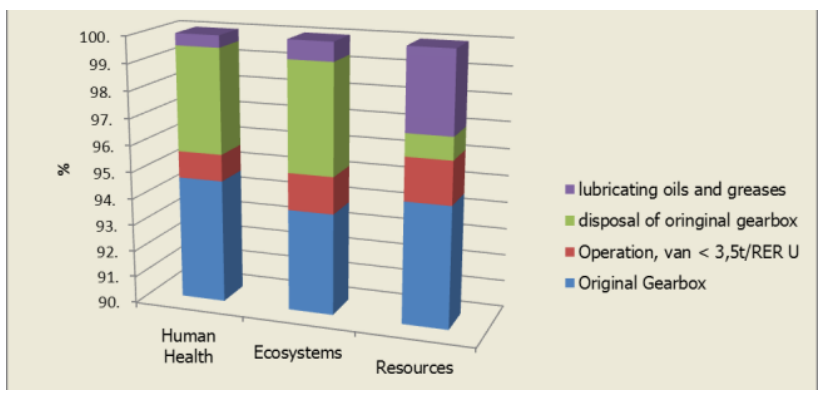

Fig. 7 Damage assessment result

Fig. 7 shows the damage assessment result in endpoint categories including human health, ecosystems, and resources. The original gearbox shares the largest ecological impact, which is shown as blue bar sharing from $93 \%$ to $94 \%$ of all three categories, among others. In resources category, the additional life cycle of lubricating oils and greases shares about 3\%. Disposal of original gearbox shares about $1 \%$. Operation of van shares about $2 \%$. In human health category, operation of van shares about $1 \%$, disposal of original gearbox shares about $4 \%$. The additional life cycle of lubricating oils and greases shares less than $1 \%$. In ecosystems category, the situation is similar as that in the human health but these three shares a little bit more than that in the human health.

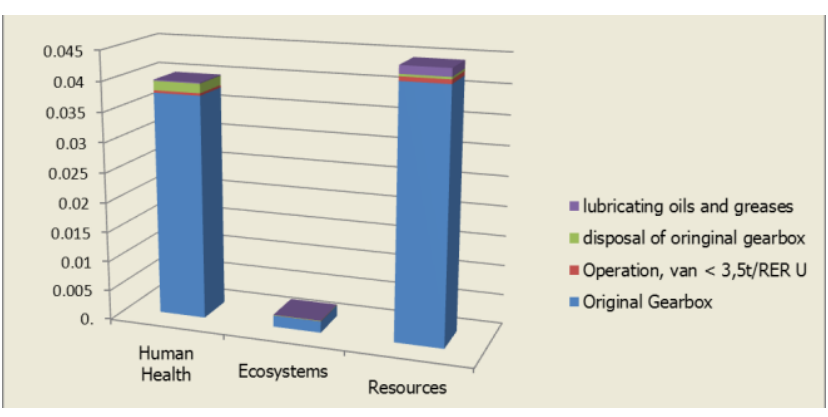

Fig. 8 Normalisation assessment result

Fig. 8 shows normalisation assessment result which is normalised by different normalisation values of each endpoint category defined by ReCiPe endpoint method Hierarchist version. In world ReCiPe endpoint hierarchist version 1.04, the normalisation values are shown in Table 14. After normalisation, the result turns into the bar chart as shown in the Fig. 8. The ecological impact of human health and resources is much higher than that of ecosystems. The original gearbox still shares the largest ecological impact in both categories. Disposal of original gearbox shares most of remaining ecological impact in human health. And the additional life cycle of lubricating oils and greases shares most of remaining ecological impact in resources. After weighting using the factor shown in the Table 14, resources reduces half of ecological impact as shown in Fig. 9. Because the weighting factor for resources is 200 and that of other two categories are 400 .

\begin{tabular}{|c|c|}
\hline Normalization-Weighting set & World ReCiPe H/A \\
\hline Normalization & 74.6 \\
\hline Human Health & 1170 \\
\hline Ecosystems & 0.0000456 \\
\hline Resources & 400 \\
\hline Weighting & 400 \\
\hline Human Health & 200 \\
\hline Ecosystems & \\
\hline Resources & \\
\hline
\end{tabular}

Table 14 normalisation and weighting values defined in the ReCiPe endpoint world hierarchist version 1.04 [6]

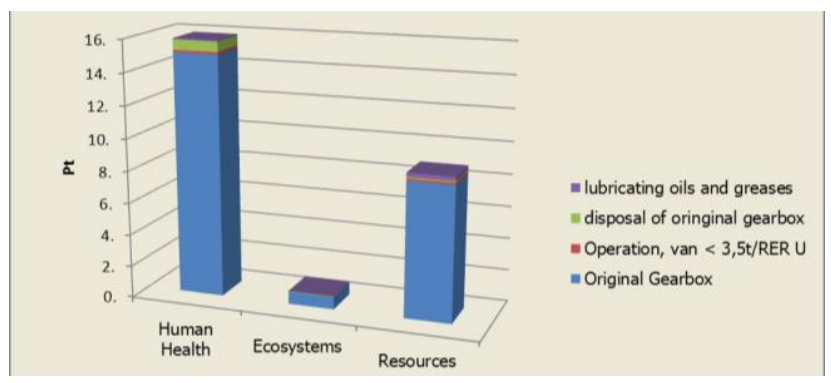

Fig. 9 Weighting assessment result

Fig. 10 shows a single score assessment result of each life cycle stage in endpoint categories. Original gearbox has the largest ecological impact, almost 25Pt in total. For original gearbox, ecological impact of human health shares the largest part, about 14 Pt. ecological impact of resources shares the second large part, about $10 \mathrm{Pt}$. ecological impact of ecosystems shares the remaining Pt., about 1 Pt. Other three have a little ecological impact only.

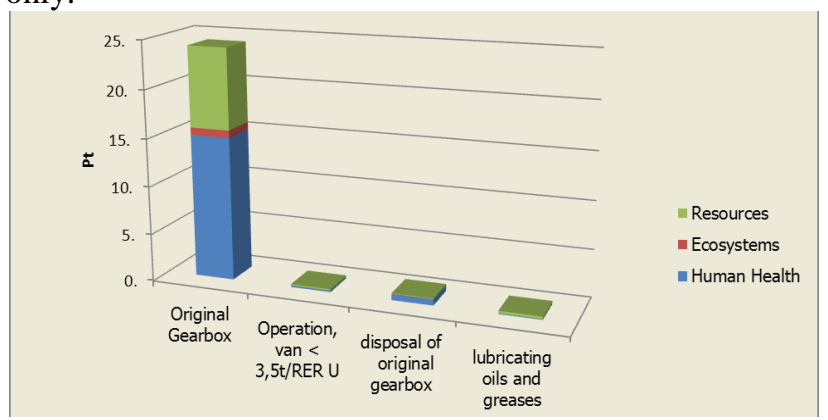

Fig. 10 Single score assessment result

Fig. 11 shows bar chart and pie chart of process contribution, which indicate the most contributed processes or materials in the life cycle. 3\% cut-off is applied to these two charts to make the presentation clearly. Pig iron and hard coal share $8 \%$ for each. They are the most contributed materials and get about $2 \mathrm{Pt}$ of ecological impact for each. Iron ore with $46 \% \mathrm{Fe}$ shares $7 \%$ as the third place. Hard coal shares $5 \%$ as the fourth 
place. Sinter of iron and cast iron are tied for the fifth place, sharing 3\%. Remaining processes share other $66 \%$.

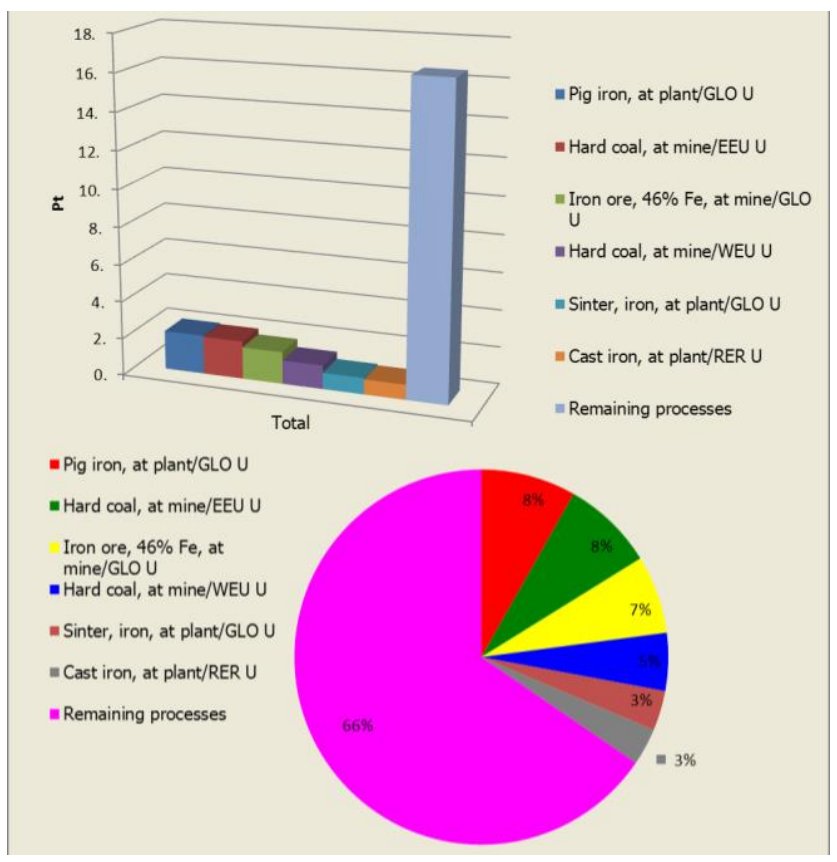

Fig. 11 Single score of process contribution

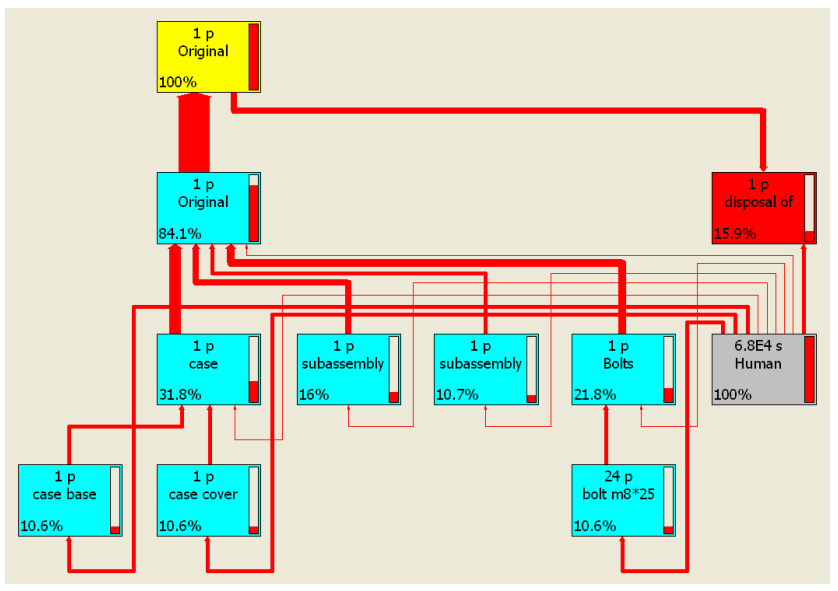

Fig. 12 Single process flow of human labour (8\% cut-off)

Human labour contributes $0.684 \mathrm{Pt}$ and shares $2.7 \%$ of the ecological impact of original gearbox life cycle, which is $25.4 \mathrm{Pt}$. In total, human labour involved 6.8E4 seconds' working time. The distribution of human labour in the whole gearbox life cycle shows in Fig. 12. The values below $8 \%$ have been cut off. Red bar in right side of each box indicates the ecological impact of human labour in every part or subassembly. Manufacture of gearbox shares $84.1 \%$ of all ecological impact of human labour. The disposal of gearbox shares remaining $15.9 \%$ of all. The subassembly of case including case base and case cover, shares the most ecological impact, $31.8 \%$ of all subassemblies. Each of the case base and the case cover shares $10.6 \%$. The subassembly of low speed shaft shares $16 \%$. The subassembly of high speed shaft shares $10.7 \%$. The subassembly of bolts shares $21.8 \% .24$ pieces of bolt $\mathrm{m} 8 * 25$ shares $10.6 \%$, which has the largest ecological impact of all bolts.
4 Analysis of results and proposal of optimisation

After the interpretation of the LCIA results, there are several points should be highlighted below.

- Turning process on steel has the most of ecological impact among all the processes used in the gearbox life cycle.

- The low-alloyed steel has the most ecological impact among the all materials used in the gearbox life cycle. Nearly half of all, $45 \%$.

- Most of the low-alloyed steel is used for manufacture of gear.

- The gear has the most ecological impact among all the parts, $29.2 \%$.

- The subassembly of low speed has the highest ecological impact, because the gear within it has the highest ecological impact.

- The manufacture of gearbox assembly produces 95.3 $\%$ ecological impact in the gearbox life cycle in this case.

- The disposal of gearbox has the second high ecological impact besides the manufacture of gearbox in the whole life cycle.

- To arrange the ecological impacts in endpoint categories in descending order are human health, resources, and ecosystems.

- The human labour contributes $0.684 \mathrm{Pt}$ and shares $2.7 \%$ of the ecological impact of original gearbox life cycle, which is $25.4 \mathrm{Pt}$.

Based on the results obtained, redesign or optimisation should be carried out in order to reduce the gearbox's ecological impact. Potential plans of optimisation may include:

$\checkmark$ To extend the service life of gearbox

$\checkmark$ To increase the recycle rate of used material

$\checkmark$ Optimisation design of gearbox structure and life cycle with eco-constraints

\section{Conclusion}

A LCA of industrial gearbox has been successfully conducted and reported in this paper. After structure analysis of the gearbox, three-tier method and parametric modelling are used to model the life cycle of the gearbox in SimaPro. The ecological impact of human labour is also involved in the LCA. A parametric approach is utilised in the modelling of gearbox life cycle. Based on the life cycle model of gearbox, the LCIA has been implemented using SimaPro with ReCiPe LCIA method. The results of LCIA consist of network, characterisation, damage assessment, normalisation, weighting, and single score. The results obtained illustrate the ecological impact of gearbox throughout its life cycle. In addition, the ecological impact of human labour is presented. Based on the analysis of results, optimisation plans are proposed at the end.

\section{References}

[1] Guinée, J.B., Gorrée, M., Heijungs, R., Huppes, G., Kleijn, R., Koning, A. de, Oers, L. van, Wegener Sleeswijk, A., Suh, S., Udo de Haes, H.A., Bruijn, H. de, Duin, R. van, and Huijbregts, M.A.J. LCA - An operational guide to the ISOstandards - Part 1: LCA in perspective (Final report, May 2001), 2001. 
[2] Baayen H. Eco-indicator 99, Manual for Designers, A damage oriented method for Life Cycle Impact Assessment, 2000.

[3] http://www.lcia-recipe.net/project-definition, January 2015.

[4] Gong G., Pan P., Chen X., and Yan L. Illustrated catalogues of Mechanical Component Curriculum Design, Harbin Institute of Technology, 1981.

[5] Su, D. and Ren, Z. Ecological Impact Assessment and Ecodesign of Industrial Gearboxes, Key Engineering Materials Vol. 486 (2011) pp 197-200, 2011.

[6] ReCiPe Mid/Endpoint

method, http://sites.google.com/site/lciarecipe/project-definition, June 2011. 